\title{
Annealing Temperature effects on the Optical Properties of CdO Thin Films Deposited by CSP Technique
}

\author{
Sami Salmann Chiad \\ Department of Physics, College of Education, Al-Mustansiriyah University, Baghdad, Iraq \\ E-mail address: samichiad2014@yahoo.com
}

\begin{abstract}
By chemical spray pyrolysis method. The $\mathrm{CdO}$ thin film prepared at constant film thickness $(350 \mathrm{~nm})$. The prepared films are annealed at a temperature of 450 and $500{ }^{\circ} \mathrm{C}$. The optical properties are calculated from the measurement of UV-Visible spectrophotometer spectrum in the range of (300900) $\mathrm{nm}$ at room temperature. The transmittance, absorption coefficient, extinction coefficient, refractive index, and skin depth are calculated as annealing temperature. The energy gap decreased from $2.52 \mathrm{eV}$ to $2.47 \mathrm{eV}$ when the annealing temperature increased from room temperature to $500{ }^{\circ} \mathrm{C}$.
\end{abstract}

Keywords: $\mathrm{CdO}$ thin film; Annealing; optical properties; Energy gap

\section{INTRODUCTION}

The films of transparent conductive oxides (TCO) such as cadmium oxide (CdO) have been extensively studied because of their use in semiconductor optoelectronic device technology ${ }^{[1]}$. Among the TCO, CdO films have been successfully used for many applications, including use in gas-sensing devices, photodiodes, transparent electrodes,photo transistors, and photovoltaic solar cells ${ }^{[2]}$.

Some researchers try to modify the synthesis procedure for $\mathrm{CdO}$ with the aim to improve chemical and physical properties of this material ${ }^{[3]}$. II-VI oxide semiconducting materials find increasing application in optoelectronic devices such as flat panel displays (FPD), photovoltaic/solar cells, heat reflectors and energy-efficient windows ${ }^{[4-6]}$.

The deposition of CdS films has been explored by different techniques, namely thermal evaporation, chemical bath deposition, chemical surface deposition, pulsed laser deposition, ion implantation, gradient re-crystallization and growth, radio-frequency magnetron sputtering and chemical spray pyrolysis ${ }^{[7-14]}$.

The films that we obtain by chemical spray pyrolysis technique (CSPT) can be useful for the scientific researches and technical applications. This is a good economic ways to get on analyses and metal salts ${ }^{[15]}$.

The aim of this study is to determine the optical parameters of $\mathrm{CdO}$ thin film prepared by chemical spray pyrolysis (CSP) method for different annealing temperatures. 


\section{EXPERIMENTAL DETAILS}

Chemical spray pyrolysis technique was used to prepare $\mathrm{CdO}$ thin films. Cadmium chloride (BDH Chemicals Laboratory, England) dissolves in redistilled water. The films were deposited on preheated cleaned glass substrates at a temperature of $400{ }^{\circ} \mathrm{C}$. The optimized conditions have been arriving at the following parameters,spray time was $10 \mathrm{~s}$ lasted by a spray interval of about (2 $\mathrm{min})$, the carrier gas was compressed air)was maintained at a pressure of $10^{5}$ Pascal, distance between nozzle and the substrate was about $28 \mathrm{~cm}$, and solution flow rate $5 \mathrm{ml} / \mathrm{min}$.

Thickness was monitored by Gravimetric method their values was about $350 \mathrm{~nm}$. The optical transmittance was recorded by using the UV-VIS spectrophotometer with a double beam (Shimadzu UV-VIS), and wavelength range (300-900) $\mathrm{nm}$. Optical properties were investigated in various annealing temperatures.

\section{RESULT AND DISCUSSIONS}

The transmittance $(\mathrm{T})$ of $\mathrm{CdO}$ thin films with various annealing temperature onto glass substrate at room temperature and for $350 \mathrm{~nm}$ thickness was calculated from the following relation ${ }^{[16]}$ :

$$
A=\log 1 / T
$$

where A: is the absorbance.

Fig. 1 show the relationship between the transmittance and wavelength, from this figure, it can be showed that the transmittance increases sharply at the wavelength of $550 \mathrm{~nm}$, and then gradually increased with increasing wavelength. The transmittance decreased with increasing annealing temperature. Before annealing, the film haslowestabsorptionedge because the amorphous film has a large band gap.

The absorption coefficient $(\alpha)$ is related to the energy band gap $\left(E_{g}\right)$ and the photon energy (hv), and could be calculated using the following relation ${ }^{[17]}$ :

$$
\alpha=\frac{20303 A}{t}
$$

where $\mathrm{t}$ : is the film thickness.

Figure 2. shows the dependence of the absorption coefficient on the photon energy for films before and after annealing. From this figure, it can show that the absorption coefficient increased with increasing annealing temperature. 


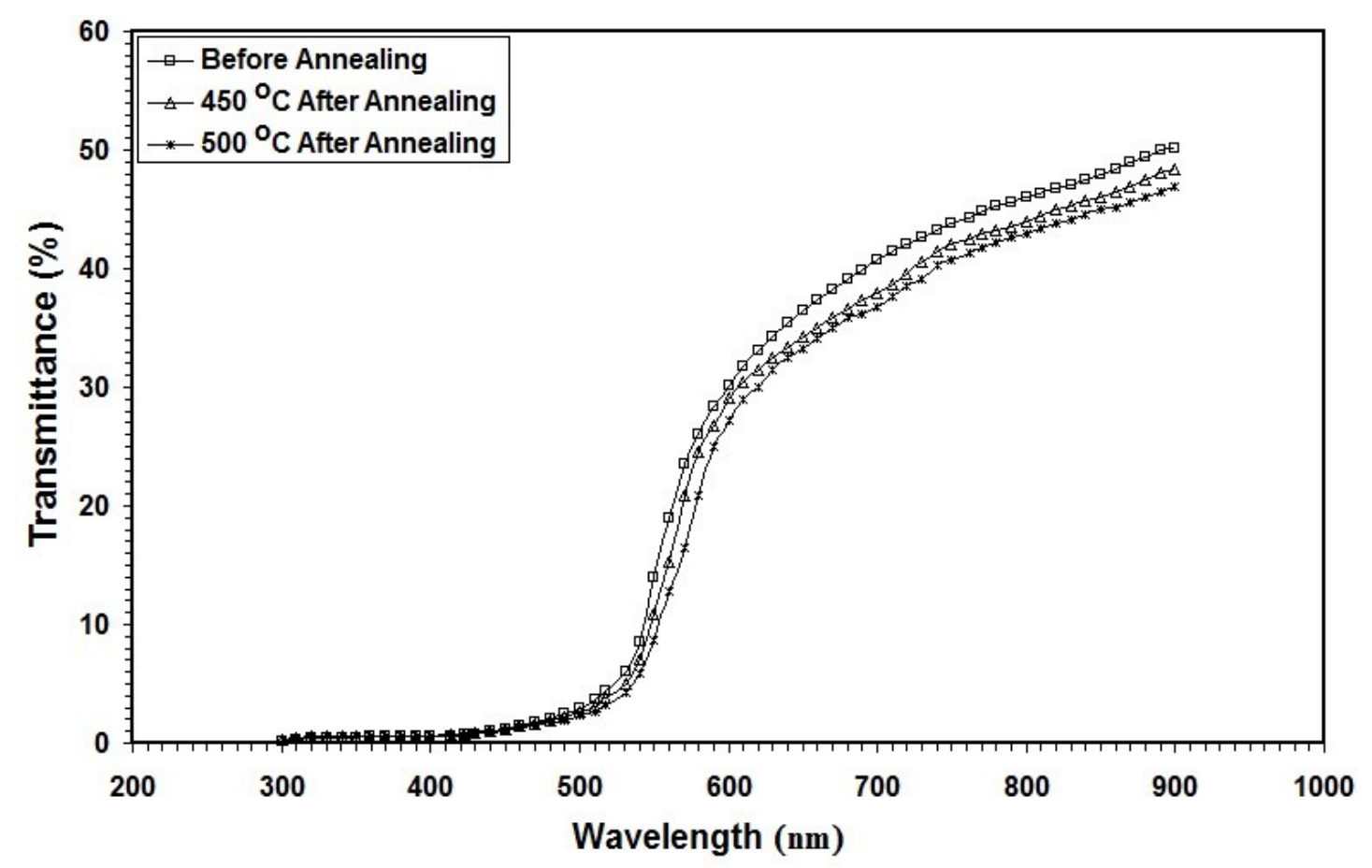

Fig. 1. Transmittance vs wavelength for various annealing temperature of $\mathrm{CdO}$ thin films.

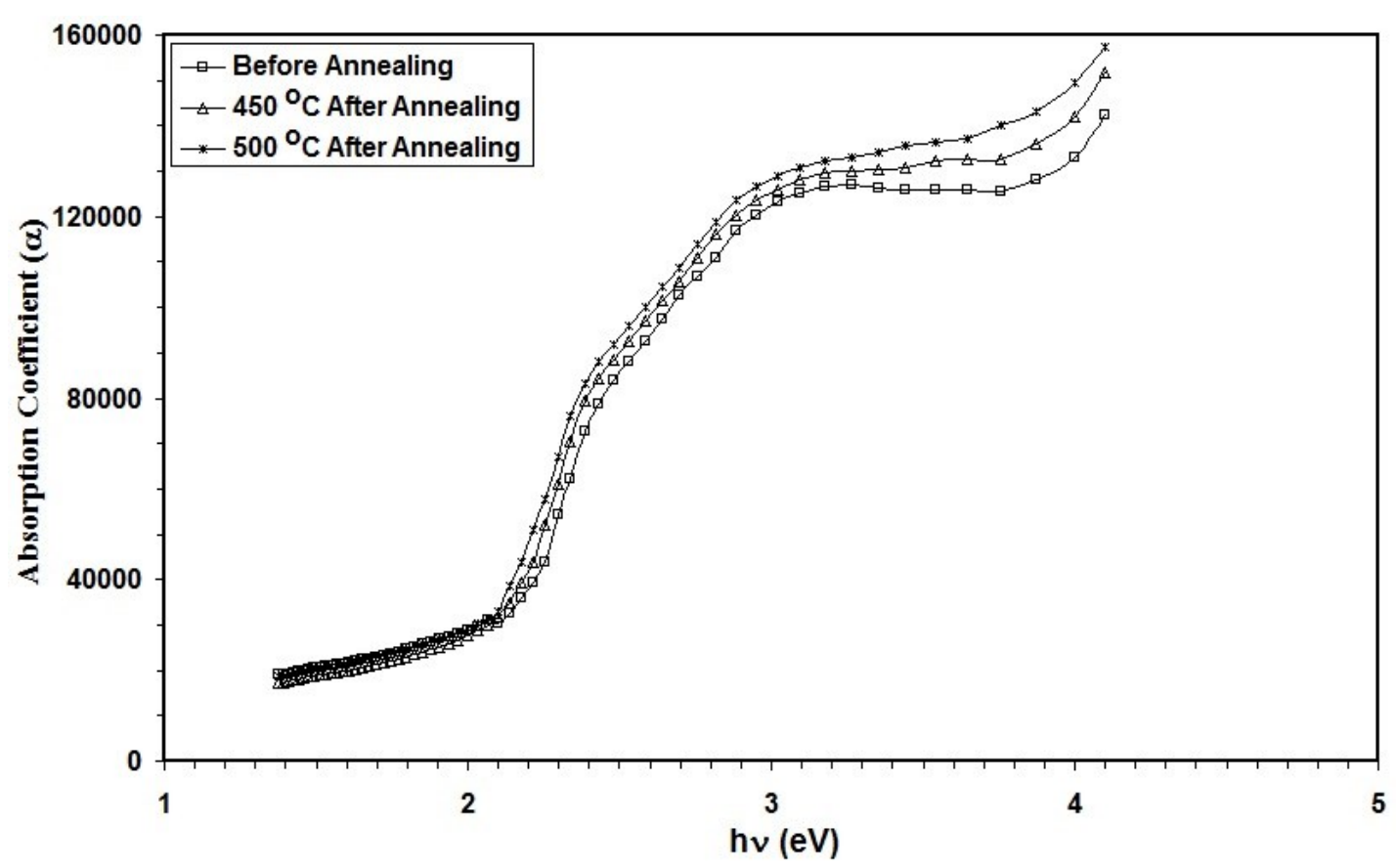

Fig. 2. Absorption coefficient vs wavelength for various annealing temperature of $\mathrm{CdO}$ thin films.

The extinction coefficient $(\mathrm{K})$ is related to the exponential decay of the wave as it passes through the medium and it is defined to be ${ }^{[18]}$ : 


$$
K=\frac{\alpha \lambda}{4 \pi}
$$

Figure 3 shows the extinction coefficient as a function of wavelength for $\mathrm{CdO}$ thin films with different different annealing temperatures. As shown in this figure, the general behavior of the extinction coefficient has increased with annealing temperature increases. The increasing of the $\mathrm{K}$ with thickness can be attributed to the increasing of the intrinsic free carrier densities in the conduction band.

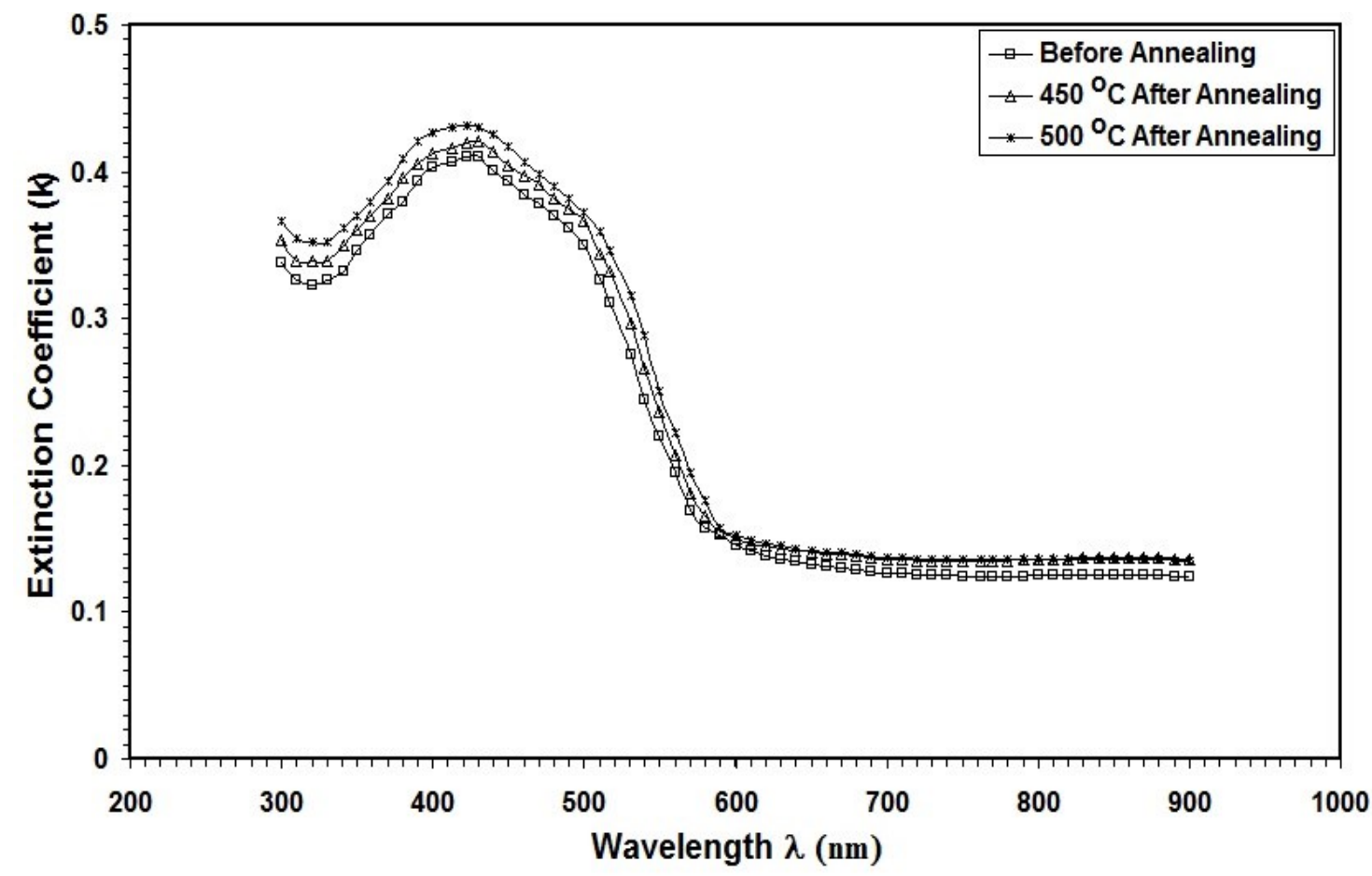

Fig. 3. Extinction coefficient vs wavelength for various annealing temperature of $\mathrm{CdO}$ thin films.

The refractive index (n) was determined from the reflectance (R) data using the relation ${ }^{[19]}$ :

$$
n=\frac{1+R}{1-R}+\sqrt{\frac{4 R}{(1-R)^{2}}-K^{2}}
$$

From Figure 4 it can show that, the maximum peak of refractive index in the wavelength of $580 \mathrm{~nm}$ and then decreased gradually with increasing wavelength for all thin 
films that prepared. In addition, it can show the increasing in the refractive index with increasing annealing temperature.

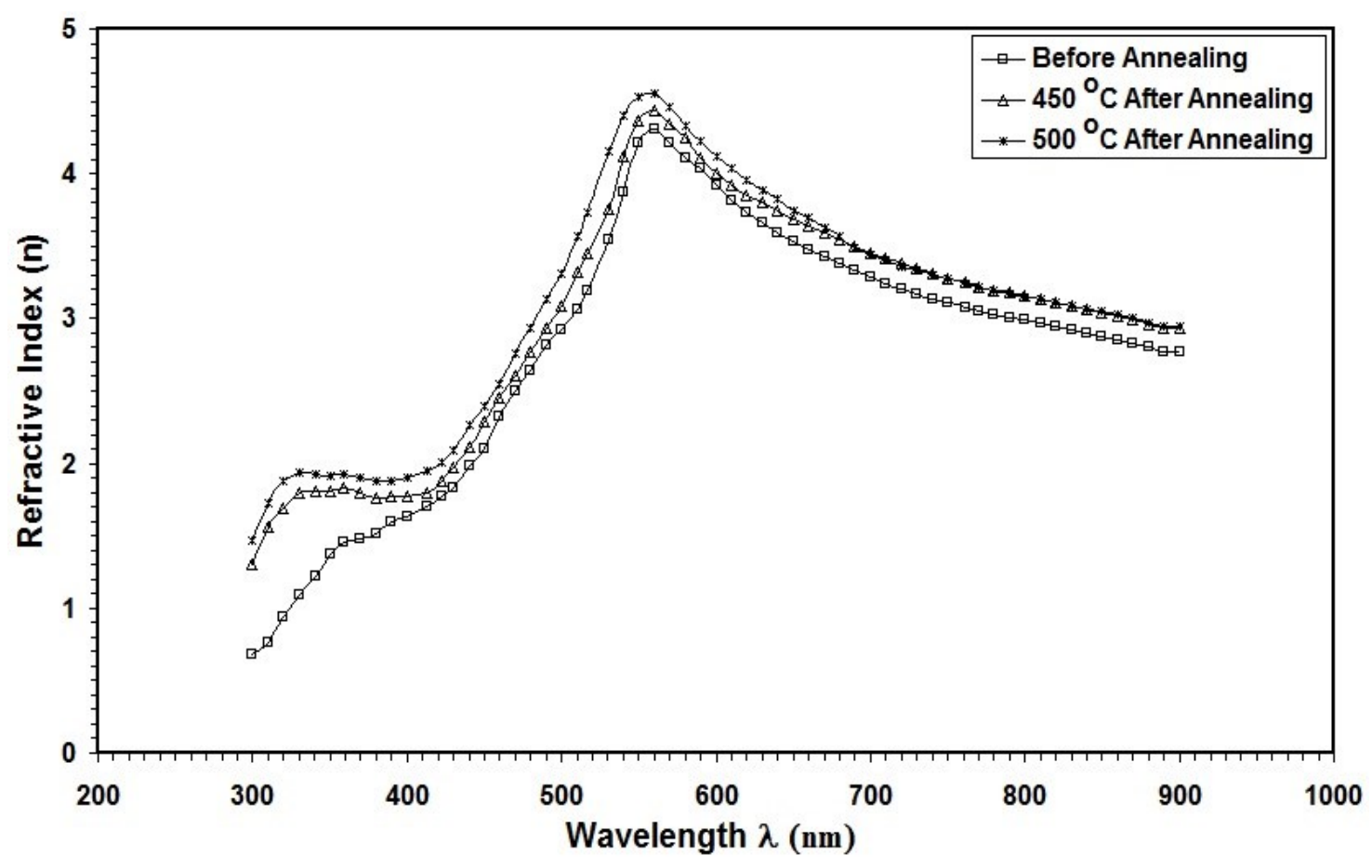

Fig. 4. Refractive index vs wavelength for various annealing temperature of $\mathrm{CdO}$ thin films.

The skin depth $(\chi)$ could be calculated using the following relation ${ }^{[20]}$ :

$$
x=\frac{\lambda}{2 \pi K}
$$

where $\lambda$ is the wavelength of the incident photon, $K$ is the extinction coefficient.

Figure (5) shows the variation of skin depth as a function of wavelength for as deposited thin films. From this figure, it can show that the skin depthincrease as the wavelength increase, this behavior could be seen for the samples, but the skin depth increases as the annealing temperature increases so the skin depth is transmittance related. $\mathrm{CdO}$ exhibits allowed direct inter band transitions. Therefore, the band gap is determined from the relation [21]:

$$
(\alpha h v)=A\left(h v-E_{g}\right)^{1 / 2}
$$

where (hv) is the photon energy, $(\alpha)$ absorption coefficient, and $\left(E_{g}\right)$ is the band gap. By plotting $(\alpha h v)^{2}$ against hv, the band gap value can be extrapolated from the straight line at $\alpha=$ 0 . From the Figures (6-8) it can show that the energy gap decreased with increasing annealing temperature from $2.52 \mathrm{eV}$ for film prepared at room temperature to $2.47 \mathrm{eV}$ for thin film annealed at $500{ }^{\circ} \mathrm{C}$. 


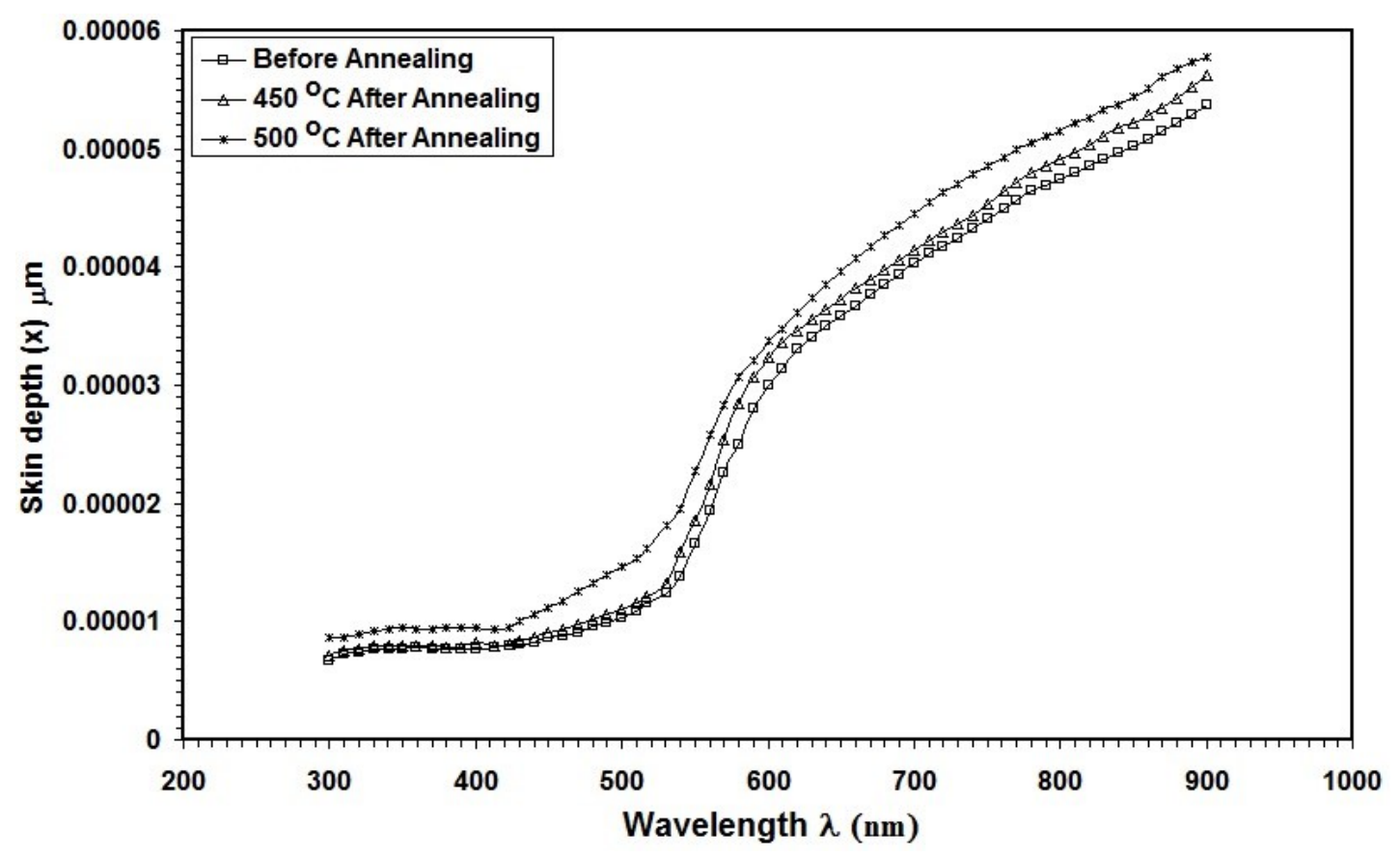

Fig. 5. Skin depth vs wavelength for various annealing temperature of $\mathrm{CdO}$ thin films.

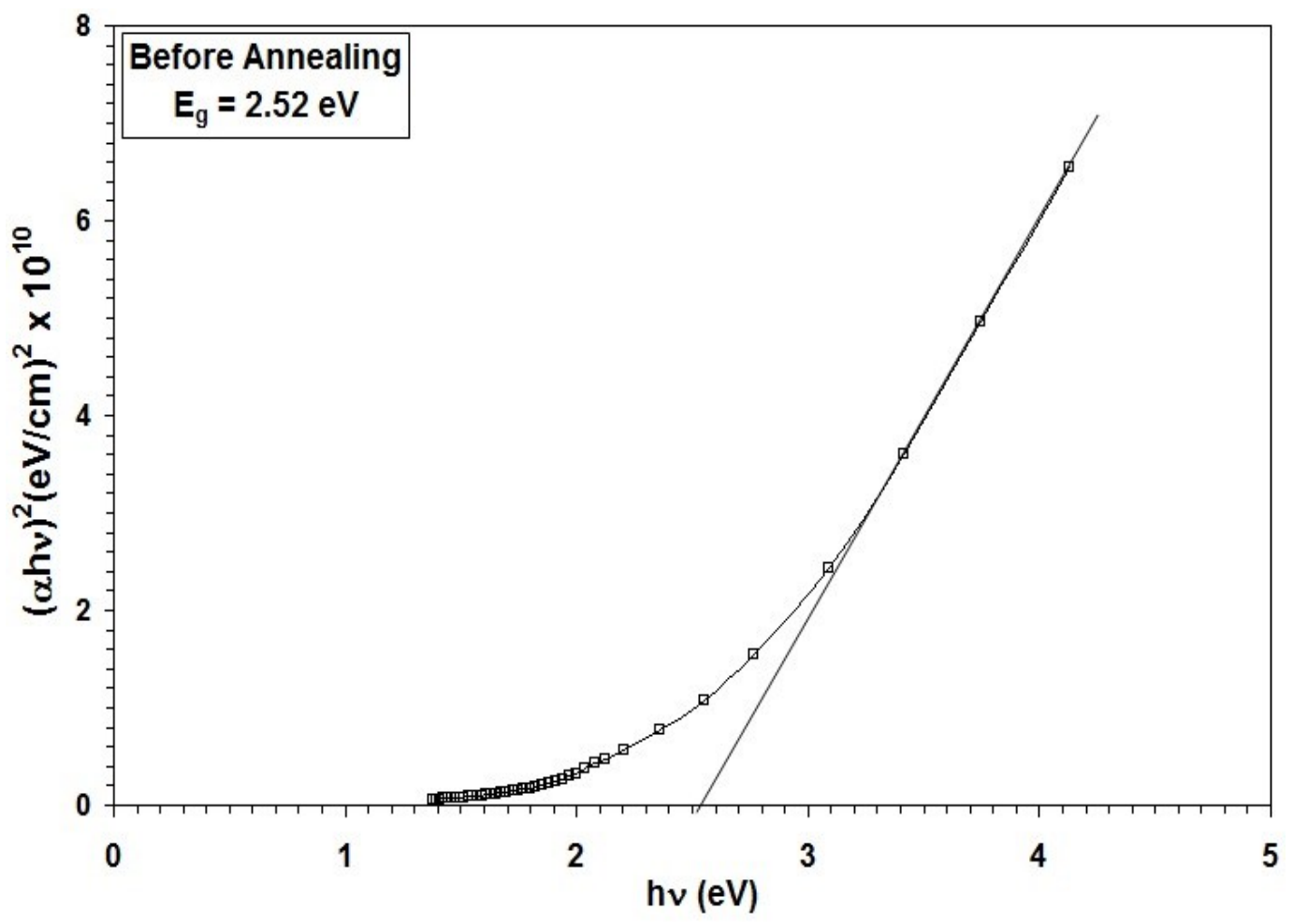

Fig. 6. Energy gapas depositedCdO thin film. 


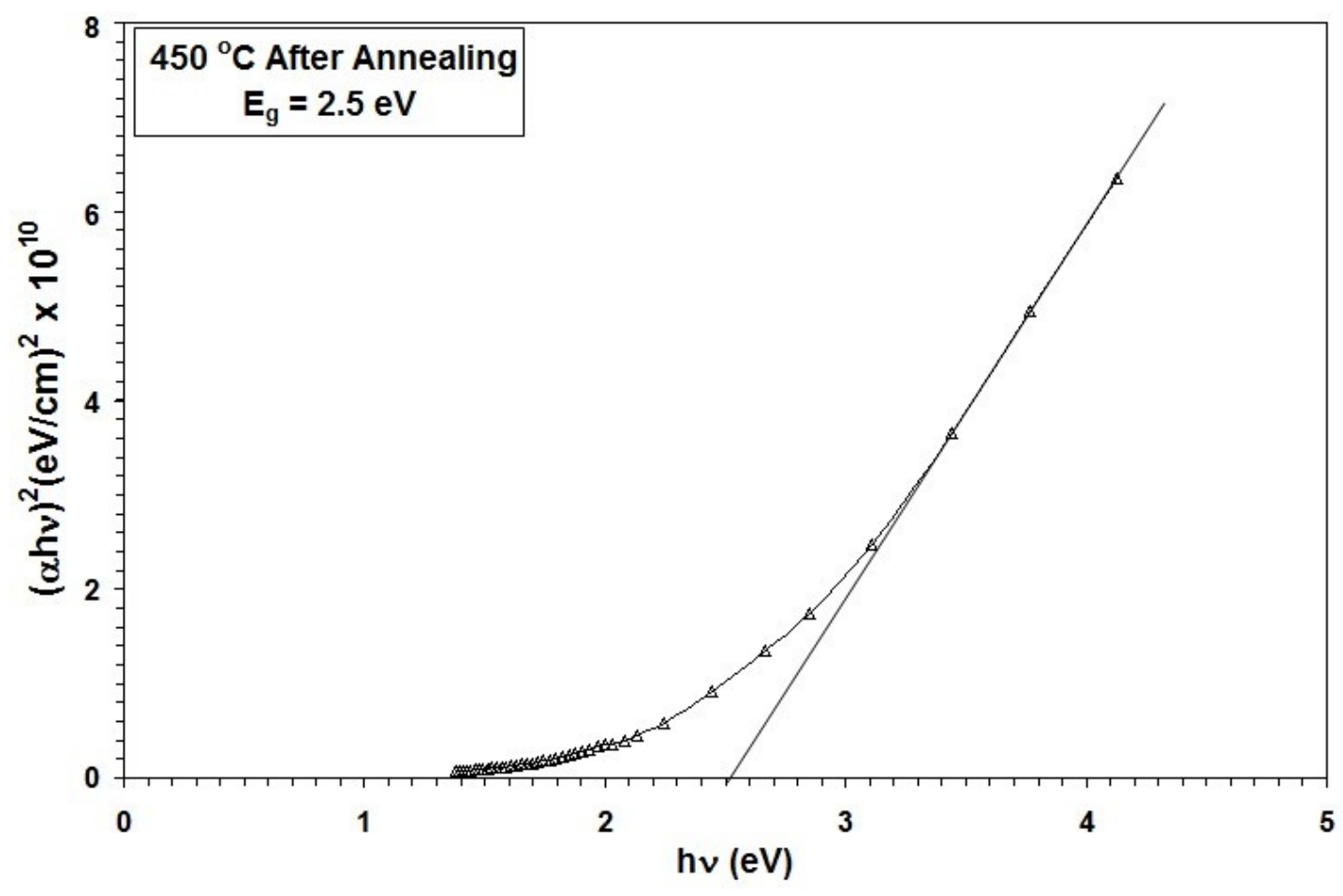

Fig. 7. Energy gapforCdO thin film after annealing temperature of $450^{\circ} \mathrm{C}$.

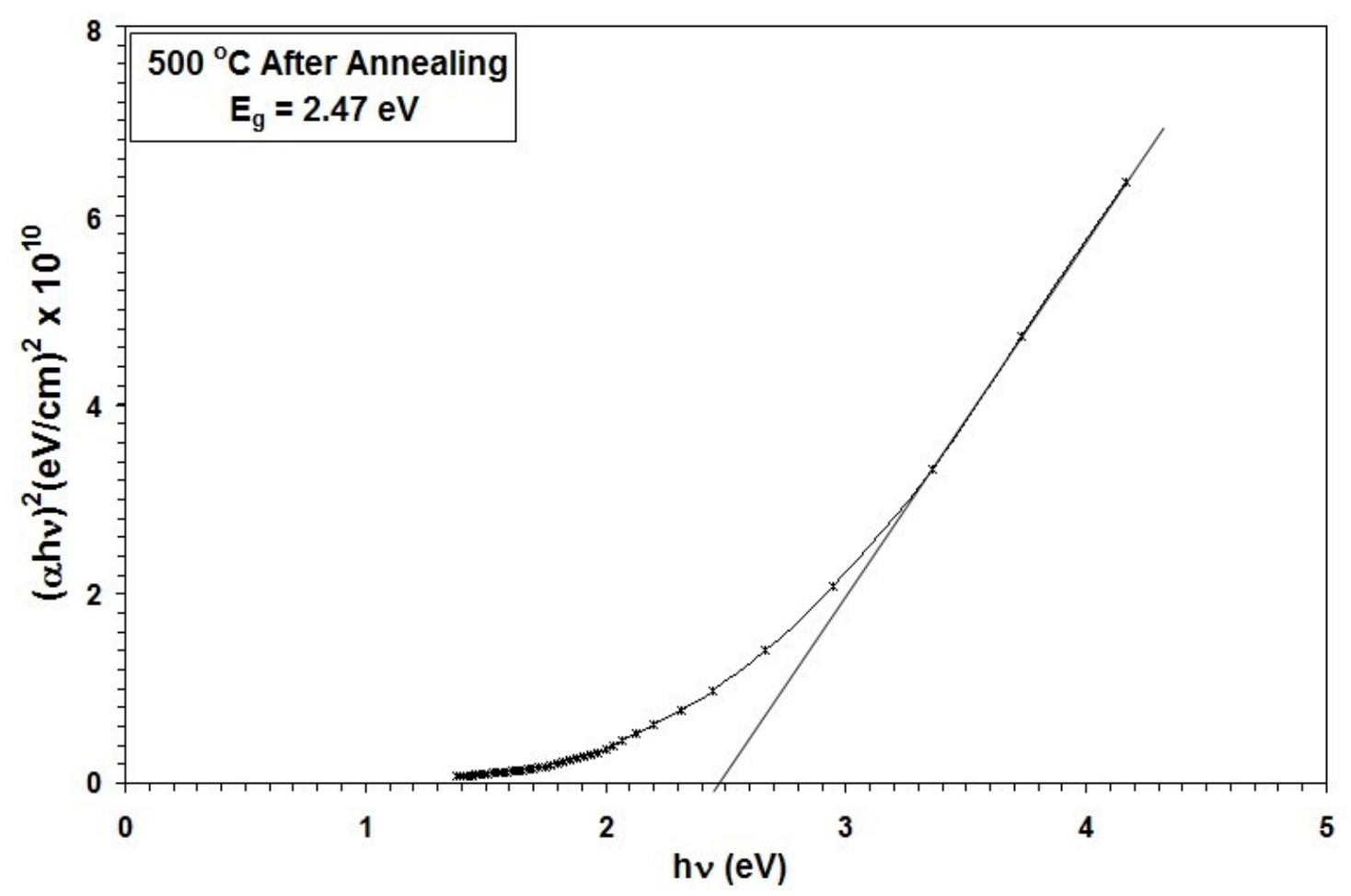

Fig. 8. Energy gap for $\mathrm{CdO}$ thin film after annealing temperature of $500^{\circ} \mathrm{C}$. 


\section{CONCLUSION}

The CdO thin film was prepared by chemical spray pyrolysis technique at a thickness of $350 \mathrm{~nm}$. The prepared films are annealed at $450{ }^{\circ} \mathrm{C}$ and $500{ }^{\circ} \mathrm{C}$, and optical properties are calculated. The transmittance decreased with increasing annealing temperature, while the absorption coefficient, extinction coefficient, refractive index, and skin depth increased with increasing annealing temperature. The energy gap decreased from $2.52 \mathrm{eV}$ to $2.47 \mathrm{eV}$ when the annealing temperature increased from room temperature to $500{ }^{\circ} \mathrm{C}$.

\section{References}

[1] Champness C.H., Chan C.H., Sol. Energy Mater. Sol. Cells. 37 (1995) 75.

[2] Liu X, Xu Z, Shen Y., Proc Int. Conf Solid State Sens. Act. 1 (1997) 585-588.

[3] A. Gulino, F. Castelli, P. Dapporto, P. Rossi, I. Fragala, Chem. Mater. 14 (2002) 704.

[4] Lima S. A. M., F. A. Sigoli, M. R. Davolos, M. Jafericci Jr. J. Alloys Comp. 344 (2002) 280.

[5] Ghosh M., C. N. R. Rao, Chem. Phys. Lett. 393 (2004) 493.

[6] Dong W., C. Zhu, Optical Mater. 22 (2003) 227.

[7] N. Benramdane, W.A. Murad, R.H. Misho, M. Ziane, Z. Kebbab, Materials Chmistry and physics 48(2) (1997) 119-123.

[8] S. Chandramohan, A. Kanjilal, S.N. Sarangi, S. Majumder, R. Sathyamoorthy, T.Som, Appl. Phys. A99 (2010) 837-842.

[9] H. Khallaf, I.O. Oladeji, G. Chai, Chow, Thin Solid Films 516 (2008) 7306.

[10] G. Ichuk, V. Kusnezh, P. Shapowal, F. Tsupko, R. Petrus, S. Tokarev, O. Horbva, J. Nano-Electron. Phys. 1(2) (2009) 36.

[11] X.L. Tong, D.S. Jiang, Z.M. Liu, M.Z. Luo, P.X. Lu, G. Yang, H. Long, Thin Solid Films 516 (2008) 2003.

[12] S. Chandramohan, A. Kanjilal, J.K. Tripathi, S.N. Sarange, R. Sathyamoorthy, T. Som, J. Appl. Phys. 105 (2009) 123507.

[13] M.L. Alor-aguilera, M.A. Gonzaez-TRUJLLO, A. Cruz-Orea, M. Tufino-Velazquez, Thin Solid Films 517 (2009) 2335.

[14] A. Podesta, N. Armani, G. Salviati, N. Romeo, A. Bosio, M. Prato, Thin Solid Films 448 (2008) 511-512.

[15] C.S. Tepantlan, A.M. Perezgonzalez, V. Arreola, Rev. Mexicana de Fisica 54(2) (2008) 112.

[16] N. F. Mott and E. A. Davis, "Electronic Processes in Non- crystalline Material",Oxford University press, Oxford, 1979.

[17] A. Ashour, Turk J Phys 27 (2003) 551-558.

[18] B. L. Sharma and R.K. Purohit, "Semiconductor Hetrojunction" Pergomon Press, New York, 1974. 
[19] N. A. Subrahamanyam: A Text Book of Optics, Ninth ed., BRJ Laboratoray Delhi, India 1977.

[20] Eloy J. F. (1984). Power Lasers, National School of Physics, Grenoble, France, John Wiley and Sons, 59.

[21] T. Mahalingam, V. Dhanasekaran, Ravi G, Lee S, Chu JP, Lim H-J., J Optoelectron Adv Mater 12 (2010) 1327-1332. 